\title{
Nurse/Midwives' practices during labor and delivery in Maternity Teaching Hospital in Erbil City
}

Lana Abdul-Hamed Muhammad Nuriy; College of Nursing, Sulaimaniya University, Sulaimaniya, Iraq. Hamdia Mirkhan Ahmed; Department of Midwifery, College of Nursing, Hawler Medical University, Erbil, Iraq. (Correspondence: hamdia.mirkhan@nur.hmu.edu.krd)

\section{ABSTRACT}

Background and objective: Labor is a life-changing event and is a high-risk time for both the fetus and the mother which affects them physically and emotionally, so proper care during labor and delivery is important. The study assessed the quality of the labor and delivery care by nurse/midwives.

Methods: A study was carried out to observe nurse/midwives' practices during the stages of labor and delivery. The study was conducted in the delivery room of the Maternity Teaching Hospital in Erbil City, during the period 28th February 2013 to 20th May 2013. The non-probability sample included 15 midwives who gave care to mothers during labor. Data were collected through a questionnaire format and observation checklist.

Results: Midwives did not perform the following practice during labor and delivery: preparing the mother (84\%), checking vital signs (93.3\%), using aseptic technique for fixing a cannula $(96.6 \%)$, providing privacy for the mother $(84 \%)$, and using sterile technique for vaginal examination, catheterization, and episiotomy (91.6\%) (91.7\%) (92.5\%) respectively, monitoring uterine contraction $(98.3 \%)$, checking the progress of labor $(93.4 \%)$ and selecting a suitable position for delivery (93\%).

Conclusion: Nurse/midwives did not provide proper care during labor and delivery. Improvements in their practice through training courses and changing hospital and delivery room policies is recommended.

Keywords: Midwife; Practice; Quality; Labor; Delivery.

\section{INTRODUCTION}

Labor is a process by which the fetus, placenta, and membranes are expelled through the birth canal [1]. Birth is a lifechanging event and the care given to women during labor has the potential to affect them both physically and emotionally in the short and long term [2]. The maternal mortality ratio at this hospital is the second highest in the region at 84 per 100,000 births, placing Iraq in a group of 68 countries globally, which account for $97 \%$ of all maternal and child deaths. This is mainly the result of poor birth practices, inadequate referral or availability of emergency obstetric care, and a high level of anemia among pregnant women (35\%), which particularly affects rural women and those in the southern and central governorates of the country [3]. Complications of labor and birth can lead to maternal and infant mortality [4], these include: premature rupture of the membranes, prolonged labor, retained placenta, excessive vaginal bleeding, malpositioning of the fetus, hypertonic uterine, primary inertia, prolonged latent 
phase, precipitate labor, uterine rupture, amniotic fluid embolism, prolapse of the umbilical cord, and meconium staining. The risks of maternal post-partum infection, hemorrhage, and infant mortality are higher in women who have a prolonged labor than those who do not. Continuous monitoring of a woman in labour and her fetus, and providing emotional support for her and her family are essential. The nurse plays a key role in providing this physical and emotional care [5]. There is an emphasis on proper care during labor in order to reduce the rate of maternal, fetal, and neonatal deaths during the perinatal period. Desired outcomes are achieved by structured nursing and midwifery care, which consists of a formalized approach to assessment of and intervention for a mother and fetus during labor. The main components are: normalize the environment; palpate to assess fetal position; encourage maternal position; assess labor pain; demonstrate cognitive, behavioral, and sensory intervention to manage labor pain; assess maternal emotional status; and use interventions to reduce emotional distress [6]. Childbirth is not a joyous event for some; it maybe a time of pain, fear, suffering, and even death. During labor and delivery, the nurse/midwives should administer sensitive and appropriate care based on the particular needs of the mother and her family. The aim of care in a normal birth is to achieve a healthy mother and fetus with the least possible level of interventio consistent with safety. Therefore, the intention of this study was to find out nurse/ midwives' practices in the labor room, regarding care during the active first phase and the second, third, and early fourth stage of labor.

\section{METHODS}

An observational study was implemented to observe the practices of 15 (from a total of 22) nurse/midwives during their care of the different stages of labor and delivery in the Maternity Teaching Hospital in Erbil City, during the period 28th February 2013 to 20th May 2013. The Maternity Teaching Hospital in Erbil City is the oldest and the only governmental maternity teaching hospital in the area. The study approved by Scientific and Ethical committee of College of Nursing/Hawler Medical University and Erbil General Directorate of Health. Nurse/midwives who were giving care during the stages of labor on three working shifts: morning (8:00am - 1:00pm), evening (1:00pm -8:00pm), and night (8:00pm - 8:00am), and those who had at least one year experience and above in delivery room were included. Nurse/ midwives who were not available during the period of data collection and those who were giving care for complicated labor such as prolonged labor and primi para's mothers were excluded. A questionnaire was designed by the researcher which consisted of nurse/midwives' background information, in addition of an observational check list to observe nurse/midwives practices during all four stages of labor through reviewing of related literature regarding standard labor and delivery care. Data were collected through interviews for collecting background information of nurse/ midwives' which took 5-10 minute, and direct observation of nurse/midwives' practices during the four stages of labor and delivery. The observation check list used included the following items: preparing mother before delivery, preparing the trolley, fixing the cannula, giving medication and fluid, sterile technique during vaginal examination, monitoring contractions, checking progress technique, monitoring amniotic membranes and fluid, catheterization technique, preparing the table for delivery, episiotomy technique, conduct during the actual delivery, newborn care 
waiting for placental separation signs, placenta delivery with care after its delivery. The duration of an observation depended on the mother's situation. Those observations, which were not completed during one shift were dropped. The nurse/ midwives were not informed regarding the researcher's observations. Each nurse/ midwives was observed four times on different shifts. The items of the observation checklist were rated as done $=1$, not done $=2$. Validity of the questionnaire and the checklist were determined through a panel of 19 experts from different related specialties. A pilot study was conducted with six nurse/midwives representing $40 \%$ of the total possible study sample. Split half reliability was determined and measured through the computation of the person-product moment correlation. The correlation coefficient was $r=0.853=85.3 \%$ which is statistically adequate. Rights and confidentiality of the participants were respected in all phases of the study. Through an informed consent process, explanation of the type and purpose of the study, confidentiality, voluntary participation and free will to withdraw were explained. It was also explained that the data were for study purposes only. The observations of the researcher were not shared with the nurse/ midwives to prevent the probability of bias in conducting the study. Data were prepared, and entered into the Statistical Package for Social Science (SPSS, version 21). Data were analyzed through the application of frequency, percentage, chisquare, and t-test.

\section{RESULTS}

The mean age and standard deviation of the 15 nurse/midwives participants was $38.80 \pm 9.48$. More than half $(53.3 \%)$ were married and had graduated from a secondary school of nursing or midwifery (see Table 1).
Table 1: Socio- demographic characteristic of nurse/midwives

\begin{tabular}{|c|c|c|}
\hline $\begin{array}{l}\text { Socio-demographic } \\
\text { characteristics }\end{array}$ & $\overline{N o}$ & $(\%)$ \\
\hline \multicolumn{3}{|l|}{ Age } \\
\hline $20-25$ & 1 & $(6.7)$ \\
\hline $26-30$ & 3 & $(20)$ \\
\hline $31-35$ & 2 & (13.3) \\
\hline$\geq 36$ & 9 & $(60)$ \\
\hline \multicolumn{3}{|c|}{$\mathrm{M} \pm \mathrm{SD} \quad 38.80 \pm 9.48$} \\
\hline Marital status & & \\
\hline Married & 8 & $(53.3)$ \\
\hline Single & 5 & (33.3) \\
\hline Divorced & 1 & $(6.7)$ \\
\hline Widowed & 1 & $(6.7)$ \\
\hline \multicolumn{3}{|l|}{ Level of education } \\
\hline $\begin{array}{l}\text { College of nursing / } \\
\text { midwifery }\end{array}$ & 2 & $(13.7)$ \\
\hline $\begin{array}{l}\text { Diploma of nursing / } \\
\text { midwifery }\end{array}$ & 1 & $(6.7)$ \\
\hline $\begin{array}{l}\text { Secondary school of } \\
\text { nursing/midwifery }\end{array}$ & 8 & $(53.3)$ \\
\hline $\begin{array}{l}\text { Primary school of } \\
\text { nursing }\end{array}$ & 2 & $(13.3)$ \\
\hline $\begin{array}{l}\text { Training course of } \\
\text { nursing }\end{array}$ & 2 & $(13.3)$ \\
\hline
\end{tabular}

More than half of nurse/midwives (53.3\%) had 1- 9 years' experience in the labor room, and $40 \%$ of the nurse/midwives worked the evening shift. The majority of them $(73.3 \%)$ had participated in training courses regarding care during labor and delivery. Sixty percent of them were satisfied with working in the delivery room; however only (40\%) believed that they were responsible for giving full care in all stages of labor (see Table 2).

The result of the current study indicate that during the active phase of labor, the majority (84\%) of nurse/midwives did not prepared the mothers. A high percentage $(60 \%)$ of nurse/midwives did not prepare the trolley, which contains the equipment required for care during labor. The majority (93.3\%) of nurse/midwives did not check the mother's vital signs. Also a high 
Table 2: Professional background of nurse/ midwives

\begin{tabular}{ccc}
\hline $\begin{array}{c}\text { Professional background } \\
\text { of nurse/midwives }\end{array}$ & No. & (\%) \\
\hline Experience in deliver room & & \\
$1-9$ & 8 & $(53.3)$ \\
$10-17$ & 3 & $(20)$ \\
$18-25$ & 2 & $(13.3)$ \\
$26-33$ & 2 & $(13.3)$
\end{tabular}

Working shifts

$\begin{array}{ll}\text { Morning shift } & 4 \\ \text { Evening shift } & 6 \\ \text { Night shift } & 5\end{array}$

Participation in training course regarding care during labor and delivery

$\begin{array}{lcc}\text { Yes } & 11 & (73.3) \\ \text { No } & 4 & (26.7)\end{array}$

Satisfaction with working in delivery room

$\begin{array}{ll}\text { Yes } & 9 \\ \text { No } & 6\end{array}$

Responsibility for giving full care for mother during all stages of labor

\begin{tabular}{lll} 
Yes & 6 & $(40)$ \\
No & 9 & $(60)$ \\
\hline
\end{tabular}

percentage (96.6\%) and (91.6\%) of them did not use aseptic techniques during fixing cannula and during vaginal examination, respectively. Almost all nurse/midwives (98.3\%) did not monitor contractions, and many $(93.4 \%)=$ did not check the steps of labor process Over half (68.3\%) of nurse / midwives monitored amniotic membrane for intact or ruptured status and characteristic of amniotic fluid. No nurse/midwives monitored the fetal heart rate. During the 2nd stage of labor, the majority of nurse/ midwives prepared the table for delivery in appropriate way $(90 \%)$ and conducted the actual delivery (81.7\%). In the second stage of labor, the majority of them did not perform following practices: using sterile technique during catheterization, selecting a suitable position for delivery, and performing episiotomy under sterile techniques. Regarding practice of nurse/ midwives during the 3rd stage of labor, the majority(66.7\%) waited for placental separation signs, did not perform newborn care after delivery (61.7\%) ; and did not perform placenta delivery and care after its delivery (93.3\%) In addition, $63.3 \%$ of nurse/ midwives they did not document delivery event (see Table 3,4). The results of the current study indicated that there were no significant differences in nurse/midwives practices during the four observations regarding preparing the mother, checking vital signs of mother, fixing the cannula under sterile technique, providing privacy for the mother, using sterile technique for the vaginal examination, monitoring contraction, checking progress of labor, monitoring amniotic membranes and fluid and monitoring fetal heart rate. While there was statistically significant differences in the practices of nurse/midwives during the four observations regarding preparing the trolley and giving medication as prescribed (see Table 5). As indicated in Table 6,there are statistically significant differences in the practices of nurse/midwives in the second stage of labor during the four observations regarding newborn care after delivery. There were no significant differences in their practices during the four observations regarding sterile technique during catheterization, preparing the table for delivery with full equipment, selecting a suitable position for delivery, performing an episiotomy under sterile technique, conducting the actual delivery, waiting for placental separation signs, and delivery of placenta with care after its delivery. 
Table 3: Overall nurse/midwives' practice during first stage of labor $(N=60)$

\begin{tabular}{lcccc}
\hline \multirow{2}{*}{\multicolumn{1}{c}{ Items }} & \multicolumn{2}{c}{ Yes } & \multicolumn{2}{c}{ No } \\
\cline { 2 - 6 } & No. & $\mathbf{( \% )}$ & No. & $\mathbf{( \% )}$ \\
\hline Prepare the mother & 10 & $(16)$ & 50 & $(84)$ \\
Prepare the trolley & 24 & $(40)$ & 36 & $(60)$ \\
Check mother's vital signs & 4 & $(6.6)$ & 56 & $(93.3)$ \\
Fix the cannula under complete aseptic technique & 2 & $(3.4)$ & 58 & $(96.6)$ \\
Giving medication as prescribe & 24 & $(40)$ & 36 & $(60)$ \\
Provide privacy of the mother & 10 & $(16)$ & 50 & $(84)$ \\
Using sterile technique for vaginal examination & 5 & $(8.4)$ & 55 & $(91.6)$ \\
Monitoring uterine contraction & 1 & $(1.7)$ & 59 & $(98.3)$ \\
Checking progressing for labour & 4 & $(6.6)$ & 56 & $(93.4)$ \\
Monitoring amniotic membrane and liquor & 41 & $(68.3)$ & 19 & $(31.7)$ \\
Checking fetal heart rate & 0 & $(0)$ & 60 & $(100)$ \\
\hline
\end{tabular}

Table 4: Nurse/midwives practice during 2 nd and 3rd stage of labor

\begin{tabular}{lcccc}
\hline \multicolumn{1}{c}{ Items } & \multicolumn{2}{c}{ Ne } & & \multicolumn{2}{c}{ No } \\
\hline \multicolumn{1}{c}{ Practice in second stage of labor } & No. & $\%$ & No. & $\%$ \\
Use sterile technique during catheterization & 5 & $(8.3)$ & 55 & $(91.7)$ \\
Prepare the table for delivery in appropriate way & 54 & $(90)$ & 6 & $(10)$ \\
Select suitable position for delivery & 3 & $(5)$ & 57 & $(93)$ \\
Performing episiotomy under sterile technique * & 2 & $(3.3)$ & 25 & $(92.5)$ \\
Conduct of actual delivery & 49 & $(81.7)$ & 11 & $(18.3)$ \\
New born care after delivery & 23 & $(38.3)$ & 37 & $(61.7)$ \\
\multicolumn{1}{c}{ Practice in third stage of labor } & & & & \\
Waiting for placental separation signs & & & & \\
Placenta delivery with care after its delivery & 40 & $(66.7)$ & 20 & $(33.3)$ \\
Documentation of delivery & 4 & $(6.7)$ & 56 & $(93.3)$ \\
\hline
\end{tabular}

* episiotomy done for 27 mothers $\mathrm{N}=27$ 
Table 5: Differences of practices in first stage of labor during four observations

\begin{tabular}{lcccccc}
\hline \multirow{2}{*}{ Items } & & \multicolumn{9}{c}{ First } & \multicolumn{2}{c}{ Observations } & \multicolumn{2}{c}{$\begin{array}{c}\text { Second } \\
\text { N (\%) }\end{array}$} & $\begin{array}{c}\text { Third } \\
\mathbf{N}(\%)\end{array}$ & $\begin{array}{c}\text { Fourth } \\
\text { N (\%) }\end{array}$ & P-value \\
\hline Prepare the mother & & & & & & \\
& Yes & $1(11.1)$ & $4(44.4)$ & $3(22.2)$ & $* 2(22.2)$ & \\
& No & $14(28)$ & $11(22.0)$ & $12(24.0)$ & $13(26.0)$ & NS
\end{tabular}

Prepare the trolley

$\begin{array}{llllll}\text { Yes } & 3(12.5) & 9(37.5) & 5(16.7) & 8(33.3) & 0.047 \\ \text { No } & 12(35.3) & 6(14.7) & 10(29.4) & 7(20.6) & \mathrm{S}\end{array}$

Monitoring mother vital sign

$\begin{array}{cccccc}\text { Yes } & 2(40) & 2(20) & 2(20) & 1(20) & \\ \text { No } & 13(24.5) & 13(24.5) & 13(24.5) & 14(26.4) & \text { NS }\end{array}$

Fix the cannula under complete aseptic technique

$\begin{array}{cccccc}\text { Yes } & 15(26.8) & 13(23.2) & 14(25) & 14(25) & 0.529 \\ \text { No } & 0(0) & 2(20) & 1(50) & 1(50) & \text { NS }\end{array}$

Give Medication as prescribed

$\begin{array}{lccccc}\text { Yes } & 3(12.5) & 9(37.5) & 5(16.7) & 8(33.3) & 0.047 \\ \text { No } & 12(35.3) & 6(14.7) & 10(29.4) & 7(20.6) & \mathrm{S}\end{array}$

Provide privacy for mother

$\begin{array}{cccccc}\text { Yes } & 1(20) & 1(11.1) & 3(40.0) & 2(40) & 0.306 \\ \text { No } & 14(26.4) & 14(26.4) & 12(22.6) & 13(24.5) & \text { NS }\end{array}$

Using sterile technique for vaginal examination

$\begin{array}{cccccc}\text { Yes } & 1(20) & 1(11.2) & 3(40) & 2(40) & \\ \text { No } & 14(26.4) & 14(26.4) & 12(22.6) & 13(24.5) & 0.306 \\ & & & \end{array}$

Monitoring Uterine Contraction

$\begin{array}{cccccc}\text { Yes } & 0(0) & 1(100) & 1(12) & 0(0) & 0.656 \\ \text { No } & 15(26.3) & 15(22.8) & 14(24.6) & 15(26.3) & \text { NS }\end{array}$

Checking progressing of labour

$\begin{array}{cccccc}\text { Yes } & 0(0) & 2(100) & 1(0) & 0(0) & \\ \text { No } & 15(26.3) & 13(22.8) & 14(24.6) & 15(26.3) & \text { NS }\end{array}$

Monitoring amniotic membrane and liquor

\begin{tabular}{llllll} 
Yes & $8(20.5)$ & $9(23.1)$ & $12(30.8)$ & $10(25.6)$ & 0.315 \\
No & $7(36.8)$ & $6(26.3)$ & $3(10.5)$ & $5(26.3)$ & NS \\
\hline
\end{tabular}

* Fisher's Exact test was applied. 
Table 6: Differences of nurse/midwives practices in 2 nd and 3rd stage of labor during four observations

\begin{tabular}{|c|c|c|c|c|c|}
\hline \multirow{2}{*}{$\begin{array}{l}\text { Items of second } \\
\text { Stage }\end{array}$} & \multicolumn{4}{|c|}{ Observations } & \multirow[b]{2}{*}{ P-value } \\
\hline & $\begin{array}{c}\text { First } \\
\text { N (\%) }\end{array}$ & $\begin{array}{l}\text { Second } \\
\text { N (\%) }\end{array}$ & $\begin{array}{l}\text { Third } \\
\text { N (\%) }\end{array}$ & $\begin{array}{l}\text { Fourth } \\
\text { N (\%) }\end{array}$ & \\
\hline \multicolumn{6}{|c|}{ Use sterile technique during catheterization } \\
\hline Yes & $3(60)$ & $0(0)$ & $1(20)$ & $1(20)$ & \multirow{2}{*}{$\begin{array}{c}0.356 \\
\text { NS }\end{array}$} \\
\hline No & $10(25.6)$ & $11(28.2)$ & $8(20.5)$ & $10(25.6)$ & \\
\hline \multicolumn{6}{|l|}{ Prepare table for delivery } \\
\hline Yes & $14(24.1)$ & $14(24.1)$ & $14(24.1)$ & $15(27.8)$ & \multirow{2}{*}{$\begin{array}{c}0.419 \\
\text { NS }\end{array}$} \\
\hline No & $1(33.3)$ & $1(33.3)$ & $1(33.3)$ & $0(0)$ & \\
\hline \multicolumn{6}{|c|}{ Select Suitable position for delivery } \\
\hline Yes & $1(50)$ & $1(50)$ & $1(50)$ & $0(0)$ & \multirow{2}{*}{$\begin{array}{c}0.519 \\
\text { NS }\end{array}$} \\
\hline No & 14(24.6) & 14(24.6) & 14(24.6) & $15(26.3)$ & \\
\hline \multicolumn{6}{|c|}{ Performing Episiotomy under sterile technique } \\
\hline Yes & $1(50)$ & $1(50)$ & $0(0)$ & $0(0)$ & \multirow{2}{*}{$\begin{array}{c}0.175 \\
\text { NS }\end{array}$} \\
\hline No & $6(24)$ & $4(16)$ & $7(28)$ & $8(32)$ & \\
\hline \multicolumn{6}{|c|}{ Conduct of actual delivery } \\
\hline Yes & $13(26.5)$ & $12(24.5)$ & $12(24.5)$ & $12(24.5)$ & \multirow{2}{*}{$\begin{array}{l}0.938 \\
\text { NS }\end{array}$} \\
\hline No & $2(20)$ & $3(20)$ & $3(30)$ & $3(30)$ & \\
\hline \multicolumn{6}{|c|}{ New born care after delivery } \\
\hline Yes & $8(36.4)$ & $7(27.3)$ & $5(22.7)$ & $3(13.6)$ & \multirow{2}{*}{$\begin{array}{c}0.052 \\
\mathrm{~S}\end{array}$} \\
\hline No & $7(18.9)$ & $8(21.6)$ & $10(27)$ & $12(32.4)$ & \\
\hline
\end{tabular}

Items of third stage

\begin{tabular}{rrrrrc}
\hline \multicolumn{2}{l}{ Waiting for placental separation signs } \\
Yes & $9(22.5)$ & $12(27.5)$ & $11(27.5)$ & $9(22.5)$ & 0.728 \\
No & $6(27.8)$ & $3(16.7)$ & $4(22.2)$ & $6(33.3)$ & NS \\
Yes & $1(11)$ & $2(50)$ & $1(25)$ & $2(50)$ & 0.571 \\
No & $14(25.9)$ & $13(24.1)$ & $14(25.9)$ & $13(24.1)$ & NS \\
Delivery of placenta with care after its delivery & & & & \\
Pes & $1(100)$ & $0(0.0)$ & $40(71.4)$ & $16(28.6)$ & 0.356 NS \\
No & $37(64.9)$ & $20(35.1)$ & $20(60)$ & $40(71.4)$ & \\
\hline
\end{tabular}

\section{DISCUSSION}

The practices of 15 nurse/midwives during the four stages of labor indicated improper practice as observed by the researcher. The majority of nurse/midwives did not properly do their complete responsibilities during labor and delivery. The early fourth stage care was completely missed. This improper practice may be due to a crowded delivery room, which has 21 occupied beds with 5 nurse/midwives on the morning shift and 3 nurse/midwives on the evening and night shifts. Other reasons for the lack of adherence to proper 
practice include the absence of guidelines to follow during care, unclear and overlapping the job descriptions of the nurse/ midwives and physicians, inadequate training course, unclear policies regarding care during labor and delivery, no identified role of nurse/midwives in documentation of finding with their signature, different level of education among nurse/midwives, and a lack of proper respect and communication with mothers. The current findings were was in agreement with finding of a study conducted in Bagdad. The researcher assessed 75 nurse/midwives practices concerning perinatal care throughout stages of labor, indicated that a low mean score and negative trends in all the following items regarding the practices during first stage of labor in monitoring and recording vital signs, checking uterine contraction, monitoring the fetal heart rate, conducting vaginal examination and rupture of membranes [7]. A descriptive study was utilized to assess the quality of midwifery care in labor and delivery room for (96) mothers in Iran. The results indicated that the lowest score was related to the assessment of vital signs, lack of emotional support, and inadequate hand washing [8].

The policies in the Maternity Teaching Hospital in Erbil City, identify that checking vital signs and monitoring the FHR is done by physician, for that reason the nurse/ midwives did not check vital signs. In spite of the fact that the partograph sheet was on the mother's chart, neither the nurse/ midwives nor the physician used it for monitoring the mother's situation in the delivery room. Partogram is a clear way to record the history, physical examination information and recording mother's labor progress [9]. Partogram use is routine in the management of labor in many countries around the world, and can be helpful in the management and decision-making process to monitor fetal and maternal wellbeing during the active stage of labor, monitoring help the midwives and the mother in achieving spontaneous vaginal delivery with low risk of both morbidity and mortality [10]. A cross- sectional descriptive study by Mathibe-Neke et al. in South Africa concluded that the proper monitoring of women during labor and continuous accurate recording on the partograph is a critical not only in intervening appropriately, but also for minimizing unnecessary interventions. Furthermore, accurate partograph recordkeeping enables an effective communication between healthcare professionals who manage the mother during labor [12].

The result of the current study indicated that the majority of nurse/midwives prepared the table for delivery in the appropriate way with full equipment. This maybe due to their experience in working in the delivery room. Preparing the place and table of birth for the delivery is one of the nurse/midwives' responsibilities, and the table is set with equipment such as sponges, drapes, scissors, basins, clamps, bulb syringe, vaginal packing, sterile gowns, and gloves, and is covered with a sterile towel, for up to 8 hours. Finding of the current study showed that the majority of nurse/midwives waited for the placental separation signs. This result is in agreement with the findings of a study conducted in Baghdad, which reported that there was high mean score with a positive trend in nurse/midwives' practice regarding the 3rd stage of labor in waiting for placental separation signs [7].

In the current study, the majority of nurse/ midwives did not perform the placenta delivery correctly including proper care after its delivery. Active management of the third stage of labor (AMTSL) is a feasible and inexpensive intervention that can help save thousands of women's lives. It involves three procedures: the use of an 
uterotonic agent (preferably oxytocin) within one minute following the delivery of the baby, delivery of the placenta with controlled cord traction, and massage of the uterus after delivery of the placenta, with palpation of the uterus to assess the need for continued massage for the two hour period following delivery of the placenta [9].

In the current study during observation in the fourth stage of labor, the researcher identified that some practices and interventions for mothers were not carry out by nurse/midwives. After the delivery of the placenta they leave the mothers and their cleaning to be done by assistant and relatives of mothers and physicians were responsible for checking the mothers' vital signs, checking the vagina for any tears or lacerations, and repairing of episiotomy. The nurse/midwives did not give instruction to the mother about perineal care, food intake, and breastfeeding. This may be due to a lack of knowledge regarding care. and a shortage of staffs and they are hurry in their job and may due to over load and crowding in delivery room. There can occur some life threatening complications during the immediate postpartum period The responsibility of nurse/midwives in the 4th stage is to frequently check the woman's physical wellbeing and blood loss, feel if the uterus is contracting, take her blood pressure and pulse as well as check her genitals for any tears or grazes, and put in stitches if necessary. During the first hour, frequent physical assessment of the mother is required. , It is necessary to take vital signs frequently, encourage the mother to pass urine within half an hour after delivery, encouraged to breastfeeding her baby as preferably within half an hour of delivery[13].

The findings of the current study are almost similar with the results of a study conducted in Khartoum, to assess midwife- ry and nursing care for patient with episiotomy The researchers of this similar study concluded that, none of the midwives gave the mother advice about pain relief, did not give information about hygiene, food intake, and they did not observe for complication post episiotomy in the first two hours [14].

\section{CONCLUSION}

Nurse/midwives working in the delivery room did not render proper care during labor and delivery and most of their responsibilities were neglected. Further studies to find the causes of this finding are necessary. Improvements in nurse/ midwives practices through proper training courses and changing hospital and delivery room policy is recommended.

\section{CONFLICTS OF INTEREST}

The author reported no conflict of interests.

\section{REFERENCES}

[1] Cunningham FG, Leveno K, Bloom S, Hauth J, Gilstrap L, \& Wenstrom K. Williams Obstetrics. 23rd ed. USA. McGraw-Hill Companies; 2010.

[2] NICE Clinical Guidelines, No. 55. London. National Collaborating Centre for Women's and Children's Health (UK). Intrapartum Care: Care of Healthy Women and their Babies during Childbirth. RCOG Press; 2007.

[3] UNCTI (United Nations Country Team Iraq). Maternal and child health. 2012. Available from: http:// uniraq.org/FlipNewsletter/UN\%20Iraq\% 20Newsletter\%20-\%20March\%202012/mobile/ index.html\#p=15, [Accessed 19 Jun 2014]

[4] Littleton L \& Engebretson J. Maternal Neonatal and Women's Health Nursing. USA. Delmar Thomson learning. 2002.

[5] Pillitteri A. Maternal \& Child Health Nursing: Care of the Childbearing \& Childrearing Family 6th edition Philadelphia. Lippincott Williams \& Wilkins. 2010.

[6] Hodnett E, Stremler R, Willan A, Weston J, Lowe N, Simpson K, et al. Effect on birth outcomes of a formalized approach to care in hospital labor assessment units. BMJ. [Internet]; 2008; 377 (100): 10211136. Available from: http://www.ncbi.nlm.nih.gov. [Accessed 20 Jul 2015]

[7] Rasheid, A. M. and Ali, R. M. (2008). Assessment of Nurse - Midwives Practices concerning perinatal care throughout stages of labor. University of Baghdad: Karbala J. Med. [Internet]. [Cited 2013 February 10]. 
2008; 2(8,9). Available from: http://www.iasj.net/iasj? func=fulltext\&ald=19189. [Accessed 2 Feb 2015]

[8] Simbar M, Ghafari F, Tork zahrani S, Majd H. (2009). Assessment of quality of midwifery care in labor and delivery words of selected Kurdistan medical science university. 2009; 22(3): 266-277. Available from: http://www.emeraldinsight.com/journals. [Accessed 12 Feb 2015]

[9] WHO. The WHO pantograph. Available from: http:// books.mcai.org.uk/2.3.\%20Managing\%20normal\% 20labour\%20and\%20delivery.1.5MB/part3.htm. [Accessed 20 May 2015]

[10] Lavender, T., Aifirevic, Z. \& Walkinshaw S. Effect of Different Partogram Action Lines on Birth Outcome . 2006.

[11] Mathibe-Neke JM, Lebeko F. L. 2 and Motupa B. The partograph: A labour management tool or a midwifery record? 2013; 5(8), DOI 10.5897/IJNM2013.0115 ISSN 2141-2456 (c) 2013 Available from: http:// www.academicjournals.org/article/ article1385033884_Mathibe-Neke\%20et\%20al.pdf. [Accessed 15 Mar 2015]

[12] POPPHI. Active Management of the Third Stage of Labor Data Obtained from Home Deliveries in the Cirebon District. 2006. Available from: https:// www.path.org/publications/files/ MCHN_popphi_amtsl_rpt_cirebon.pdf. [Accessed 4 Jun 2015]

[13] Kaur N, Kaur SPK.Skill development of Nurses in Managing the fourth stage of Labour. Saha Nursing and Midwifery Research Journal.2014;10(1).

[14] Khaier MGM. Assessment of midwifery and nursing care for patients with episiotomy in Albanjadeed Teaching Hospital. Thesis, Univerisity of Medical Sciences and Technology, 2006. 